\title{
Vascular adaptation in pregnancy and endothelial dysfunction in preeclampsia
}

\section{S Boeldt and I M Bird}

Department of Ob/Gyn, Perinatal Research Laboratories, University Wisconsin - Madison, Madison, Wisconsin, USA
Correspondence should be addressed to I M Bird Email

imbird@wisc.edu

\begin{abstract}
Maternal vascular adaptation to pregnancy is critically important to expand the capacity for blood flow through the uteroplacental unit to meet the needs of the developing fetus. Failure of the maternal vasculature to properly adapt can result in hypertensive disorders of pregnancy such as preeclampsia (PE). Herein, we review the endocrinology of maternal adaptation to pregnancy and contrast this with that of PE. Our focus is specifically on those hormones that directly influence endothelial cell function and dysfunction, as endothelial cell dysfunction is a hallmark of PE. A variety of growth factors and cytokines are present in normal vascular adaptation to pregnancy. However, they have also been shown to be circulating at abnormal levels in PE pregnancies. Many of these factors promote endothelial dysfunction when present at abnormal levels by acutely inhibiting key $\mathrm{Ca}^{2+}$ signaling events and chronically promoting the breakdown of endothelial cell-cell contacts. Increasingly, our understanding of how the contributions of the placenta, immune cells, and the endothelium itself promote the endocrine milieu of PE is becoming clearer. We then describe in detail how the complex endocrine environment of PE affects endothelial cell function, why this has contributed to the difficulty in fully understanding and treating this disorder, and how a focus on signaling convergence points of many hormones may be a more successful treatment strategy.
\end{abstract}
Key Words
- preeclampsia
- endocrinology
- pregnancy adaptation
- $\mathrm{Ca}^{2+}$
- cytokines

\section{Introduction}

Preeclampsia (PE), a hypertensive disorder of pregnancy, has been described for centuries, and the physiology has been studied intensively for decades. Still, effective therapies have proven elusive. One barrier to our understanding of this disease of pregnancy is our incomplete understanding of what constitutes a healthy pregnancy. Drastic anatomic and physiologic changes occur in the mother, including substantial redistribution of blood flow to meet the needs of the developing fetus. In basic terms, we can describe the gross changes, which permit a healthy maternal vasculature in pregnancy, but our understanding is more limited in terms of how the body coordinates the necessary adaptive processes from the molecular level to the organ/organ system level. A growing body of evidence points to the disruption of these incompletely understood processes as potential mediators of the symptoms of PE. More specifically, although many studies point to the vascular endothelium as a tissue that is profoundly changed (develops enhanced or 'adapted' function) by the environment of healthy pregnancies, 
it can also become dysfunctional in pregnancies, which develop preeclampsia. In this review, we attempt to describe the critical endothelial changes necessary to provide a healthy pregnancy. We will begin with a narrow focus on the endocrine regulation of healthy pregnancy, so that we will then be able to highlight the endocrine disruption, which has more recently been described in PE pregnancies. We will finish by reviewing the mechanisms by which this altered endocrinology of PE may promote physiologic changes underlying the clinical symptoms most commonly manifest in PE pregnancies and how that may be targeted for novel therapy.

\section{Physiologic and anatomic adaptation of vasculature to pregnancy}

\section{Implantation and early vascular remodeling}

Although it could certainly be argued that hormonal changes associated with the menstrual cycle prepare the uterus for any impending pregnancy, maternal recognition of pregnancy and corresponding early vascular adaptation only begins at embryo implantation into the decidua. This occurs shortly after the embryo descends into the uterus from oviduct. Soon after implantation, cytotrophoblast invasion into the endometrium initiates the early stages of placentation (Page et al. 1972). Syncytiotrophoblast migration then begins remodeling of decidual uterine spiral arteries in the first trimester, forming sinuses, which will eventually become placental villi. In the second trimester, myometrial spiral arteries are remodeled from high-resistance, coiled vessels to dilated low-resistance vessels (Robertson et al. 1975). Transformation of the myometrial spiral arteries greatly increases and indeed slows blood flow to the intervillous space of the developing placenta, facilitating exchange of gas and nutrients with the growing fetal circulation while protecting the fetal vessels themselves.

\section{Physiologic adaptation to pregnancy}

Beyond the placenta, pregnancy also has profound effects on uterine vascular physiology and, to a lesser degree, systemic vascular physiology. With the hormonal changes of pregnancy comes an increase in maternal blood volume and increased cardiac output, which is normally matched or even slightly exceeded by a drop in vascular resistance. Maternal blood volume begins to rise early in pregnancy (6- to 8-week gestation), until reaching a maximum as much as $50 \%$ greater than that during the non-pregnant state. Cardiac output increases with the rise in heart rate and stroke volume, totaling a $30-50 \%$ increase during pregnancy. The majority of the gestational change in cardiac output occurs early in pregnancy, typically in the first 8 weeks of gestation (Clark et al. 1989). The reason a gestational increase in blood volume and cardiac output does not increase blood pressure is that there is a general decrease in vascular resistance, and although a drop in vascular resistance occurs throughout the body, there is a disproportionately large drop in vascular resistance in the uterine circulation. The outcome is that a greater proportion of the cardiac output goes to the uteroplacental unit to meet the needs of the growing fetus. Estimates of the dramatic changes in uterine blood flow during pregnancy range from 30- to 50-fold increases compared with the non-pregnant state (reviewed in Sladek et al. 1997, Bird et al. 2003). The drop in vascular resistance is often primarily attributed to the remodeling of the spiral arterioles mentioned previously, but further drops in uterine vascular resistance are also achieved through mechanisms of uterine vascular remodeling and sustained vasodilation. Although many researchers focus on the importance of changes in the smaller 'resistance vessels', it should also be noted in the face of a 30- to 50-fold increase in flow; this control point is only maintained because distributing vessels show a considerable increase in diameter and changes in both tone and increased vasodilatory capacity.

\section{Anatomic adaptation to pregnancy}

Angiogenesis is by definition the growth of new vessels from preexisting vessels. Most vasculature in healthy adult tissues is rather quiescent in this respect, with maintenance of existing vasculature being far more common than creation of new vessels. Uterine vessel growth throughout the menstrual cycle and during pregnancy is a welldocumented exception. Many suggest that angiogenesis occurs as the result of an overall net abundance of proangiogenic signals over that of anti-angiogenic signals. In tumor angiogenesis, which dominates the literature, these signals are generally thought to consist of growth factors and cytokines. Although these signals are also at the heart of angiogenesis in the gravid uterus, there are also those who believe that the hormones of pregnancy (namely, human chorionic gonadotropin, estradiol and progesterone) can assist in tipping the balance toward angiogenesis (Pepper 1997, Fraser \& Lunn 2000), 
in addition to the locally elevated growth factors and cytokines present at the site of implantation and placentation. Further physiological adaptation of the uterine vasculature includes outward hypertrophy and vessel lengthening (Palmer et al. 1992, Osol \& Mandala 2009). Outward hypertrophy refers to increased vessel diameter, typically through vascular smooth muscle cell hypertrophy, which is likely accompanied by endothelial hyperplasia (endothelial hypertrophy is also possible, although it is yet to be studied in human pregnancy) to cover the increased surface area of the outwardly growing vessel. The maternal uterine arteries are also thought to elongate, at least as reported in animal studies (reviewed in Osol \& Mandala 2009). The net result of outward hypertrophy (decreased resistance), vessel lengthening (increased resistance) and angiogenesis (decreased resistance) during pregnancy is an increase of overall vessel cross-sectional area, and therefore, a drop in vascular resistance in the tissue. It is this local drop in vascular resistance that preferentially shunts blood to the uterus and thus to the placenta, ensuring adequate gas, nutrient and waste exchange in a healthy pregnancy. In the ewe, where it has been studied most thoroughly, uterine artery angiogenesis primarily occurs in the early stages of pregnancy, as the structures created will be necessary to support the greater amount of uterine blood flow demanded by the fetus in late gestation (Magness \& Zheng 1996, Bird et al. 2003). By late gestation (3rd trimester), the vessel architecture of the uterus is essentially developed and any further increases in blood flow are now dependent on a sustained vasodilation of those existing vessels. Clinically, it is the mid-to-late gestation period when most cases of PE present themselves to physicians, and PE subjects are known to show reduced capacity for vasodilation (Kenny et al. 2002, Yamamoto et al. 2010, Krupp et al. 2013).

\section{Vasodilation in pregnancy}

Throughout pregnancy, but especially from mid-gestation through parturition, adequate uteroplacental blood flow is highly dependent on vasodilation. It is clear that pregnancy adaptive increases in endothelial cell vasodilator production are necessary to maintain a healthy pregnancy. Indeed, to prevent hypertension, increased vasodilator production also occurs throughout the systemic circulation (Poston et al. 1995, Suzuki et al. 2002), and a failure of systemic vascular endothelial function has even been reported in hand vein endothelial cells of PE subjects (Mahdy et al. 1998). The vascular endothelium of the uterine arteries can increase their capacity to produce vasodilators to multiple agonists by increasing the expression of key mediators of vasodilator production. Concomitantly, the endothelium also reorganizes the post-receptor signaling in such a way that it can achieve greater and more sustained signaling responses to vasodilator-stimulating signals (i.e. hormones, shear stress and mechanical stress) to activate in turn greater and more sustained vasodilator synthesis (Bird et al. 2003). Of particular note, a common activating mechanism for many vasodilators is the elevation of intracellular free $\mathrm{Ca}^{2+}$ concentration $\left(\left[\mathrm{Ca}^{2+}\right]_{\mathrm{i}}\right)$. One important way $\left[\mathrm{Ca}^{2+}\right]_{\mathrm{i}}$ responses can be amplified and sustained is through promoting intercellular signaling through gap junctions. Once more coordinated and synchronous signaling events are achieved, there is not only an increase in vasodilator output per cell but also a recruitment of more cells to respond to the external stimuli. More specifically, periodic, transient $\mathrm{Ca}^{2+}$ burst events have been shown in endothelial cells in response to vasodilatory stimuli and to be highly dependent on gap junction coupling through the connexin 43 (CX43) isoform (Yi et al. 2010). If CX43 function is blocked, sustained $\mathrm{Ca}^{2+}$ burst responses are lost, and increased vasodilator production due to pregnancy adaptation returns to non-pregnant levels. The following sections will now discuss how common vasodilators are regulated in pregnancy to maintain adequate uterine blood flow to the placenta.

Nitric oxide Nitric oxide (NO) production in the endothelium is catalyzed by the enzyme endothelial nitric oxide synthase (NOS3, also known as eNOS) to produce NO and L-citrulline from L-arginine, $\mathrm{O} 2$ and NADPH. The role of $\mathrm{NO}$ in regulating vascular tone is as a soluble gas, which diffuses from the endothelium to the vascular smooth muscle, promoting cGMP production, which ultimately results in smooth muscle relaxation. Phosphorylation events at multiple positions on NOS3, along with elevated $\left[\mathrm{Ca}^{2+}\right]_{\mathrm{i}}$ levels, largely determine endothelial NO output. Tran and coworkers investigated the role of specific NOS3 phosphorylation sites on $\mathrm{Ca}^{2+}$ sensitivity of the enzyme in vitro (Tran et al. 2009). Although phosphorylation of NOS3 itself was not sufficient to cause activation, the phosphorylation of S1179 and S617 in particular increased the sensitivity of NOS3 to $\mathrm{Ca}^{2+}$-dependent activation. Both these phosphorylation events have been shown to occur in uterine artery endothelial cells during pregnancy in response to vasodilatory stimuli (Cale \& Bird 2006). Studies have shown reduced uterine blood flow in pregnant animals after infusion with the NOS3 inhibitor

Published by Bioscientifica Ltd. 
L-NAME (Sladek et al. 1997), linking endothelial NO production to pregnancy adapted vasodilation. Indeed, the role of NO in pregnancy adaptation has been reviewed extensively (Boeldt et al. 2011). Of note, although it is true that NOS3 expression levels are increased during pregnancy in uterine artery endothelium (Magness et al. 1997), changes in $\mathrm{Ca}^{2+}$ signaling are the necessary trigger for NO production. Certainly increased expression raises the capacity of endothelium to make NO, and we have shown this contributes directly to increased NO production in pregnancy adapted uterine arteries (Yi et al. 2005). Nonetheless, it is equally important to note that in cell culture, endothelial cells from the uterine arteries of pregnant ewes lose the vast majority of pregnancy-adapted NOS3 expression difference from those cells derived from non-pregnant ewes, and yet, they still maintain pregnancy adapted elevations in NOS3 activation when stimulated with $\mathrm{Ca}^{2+-}$ mobilizing agonists (Sullivan et al. 2006). This appears to be because greater cell-cell coupling by CX43 observed in pregnancy is retained in culture and CX43 blockade both in freshly isolated vessels (Morschauser et al. 2014) and in cells in culture (Yi et al. 2010) removes $\mathrm{Ca}^{2+}$ bursting and enhanced NO output in parallel. Such observations reinforce quite clearly the critical importance of sustained $\mathrm{Ca}^{2+}$ responses to enhance NOS3 activity in pregnancy and raise the question of whether a failure of CX43-enhanced $\mathrm{Ca}^{2+}$ signaling could in turn contribute to endothelial dysfunction in PE pregnancy (Bird et al. 2013).

Prostacyclin Prostacyclin (PGI2) is a potent vasodilator derived from endothelial arachidonic acid metabolism. In general, the impact of prostacyclin on vascular tone can best be explained by the thromboxane (TX) A2/PGI2 ratio (reviewed in Mehta \& Griendling 2007). TXA2 acts as a vasoconstrictor on the vascular smooth muscle (VSM), whereas PGI2 functions as a vasodilator. Both TXA2 and PGI2 have a very short half-life, and as such, only indirect measures can be made of stable metabolites in the circulation/media (TXB2 and 6-keto PGF2A respectively). Because the effect of PGI2 is tightly tied to TXA2 and metabolites, both must be measured and compared in order to draw conclusions for net effects on VSM tone. Unfortunately, there are no techniques that allow monitoring of PG or TX class molecules in real time. Although the system is more difficult to monitor, there is strong evidence that PGI2 plays an important role in pregnancy-adapted vasodilator responses. Some groups have found elevated levels of PGI2 metabolites in pregnancy compared with the non-pregnant state
(Lewis et al. 1980, Goodman et al. 1982). There are many reports of upregulation of cyclooxygenase (COX) enzymes (predominantly COX1 in endothelial cells) during pregnancy, which increase throughout gestation, thereby increasing the cellular capacity for PGI2 production (Janowiak et al. 1998, Habermehl et al. 2000, Magness et al. 2000). Lastly, PGI2 production is known to be the result of cPLA2 activation, and cPLA2 in turn also undergoes $\mathrm{Ca}^{2+}$ sensitive activation (Bird et al. 2000). Even though PGI2 cannot be studied directly in real time, as we can for NO, and certainly not on an individual cell basis, it is highly likely that the changes in $\mathrm{Ca}^{2+}$ signaling within cells and between cells, which regulate NO production apply much in the same manner as PGI2.

EDHF Endothelium-derived hyperpolarizing factor (EDHF) has also been implicated as a third major player in endothelial cell-mediated vasodilator production in pregnancy. It has also become clear, however, that 'EDHF' is not a single factor, but a spectrum of responses that are otherwise neither NO nor PGI2 mediated, but still result in smooth muscle relaxation. Currently, it seems that although EDHF and NO/PGI2 are most likely redundant pathways, a significant portion can be attributed to EDHF, and it is fair to say in the absence of EDHF, the maternal circulation would struggle to provide adequate blood flow to the fetus. Progress in the EDHF field is limited by this ongoing debate on the identity of the active compound(s), and tools to monitor it are comparatively crude. Although not unanimous, a number of studies agree that pregnancy-specific upregulation of agonist-induced vasodilation includes an EDHF component (reviewed in Morton \& Davidge 2013). As with NO and PGI2, $\mathrm{Ca}^{2+}$ signaling plays an important part in mediating at least some forms of EDHF production, further complicating the role of each respective vasodilator in pregnancy adaptation. Of note, 2-APB, which effectively inhibits both $\left[\mathrm{Ca}^{2+}\right]_{\mathrm{i}}$ burst signaling and corresponding NO production in uterine artery endothelium (Yi et al. 2005, Gifford et al. 2006), has also been argued to be an effective inhibitor of EDHF function (Griffith 2004). An important consideration in the role of EDHF in pregnancy-adapted vasodilator production is that the relative contribution of NO, PGI2 or EDHF may be dependent on vascular bed or vessel size (Morton \& Davidge 2013), and this is observed in both humans and in animal models. Although EDHF plays an important role in augmenting increased uterine blood flow, if not causing it in certain situations, it also seems likely that changes in $\left[\mathrm{Ca}^{2+}\right]_{i}$ signaling may be equally important to NO, PGI2, and

Published by Bioscientifica Ltd 
EDHF function given the action of 2-APB in each case. Consistent with this, it is also relevant that we reported recently that the endothelial cells of umbilical cords from PE women near term show defects in sustained and coordinated endothelial $\mathrm{Ca}^{2+}$ bursting (Krupp et al. 2013) and although NO output was measured and a decrease was observed, we did not measure PGI2 or EDHF.

\section{Hormonal control of vascular adaptation}

\section{Sex steroids}

Underlying the extensive remodeling of the uteroplacental vasculature during pregnancy are numerous endocrine changes. These endocrine changes include fluctuations in circulating sex steroids, which truly begin to change through the menstrual cycle in preparation for pregnancy. Estrogens and progesterone are known to have profound effects on the maternal vasculature, especially in the uterine arteries. As the circulating levels of these hormones change through pregnancy, so do their effects on maternal vascular function.

Estrogen Estrogen in its various forms has a number of important effects on maternal vascular adaptations to pregnancy. In a rat model, de novo synthesis of estrogen during decidualization assists in angiogenesis at the implantation site (Das et al. 2009), which is essential for maintaining early pregnancy. As gestation continues and the critical regulator of vascular resistance switches from angiogenesis and vasodilation to almost exclusively vasodilation, the effects of circulating estrogens also switch to promoting vasodilation. Estrogens are well known to promote vasodilator production, but estrogen alone is not effective in the activation of $\mathrm{Ca}^{2+}$ signaling in UAEC (Chen et al. 2004). Rather the effects of estrogen on NO and PGI2 production may be more through genomic regulation downstream of estrogen receptor (ER)A and ERB by directly promoting NOS3 and COX1 expression. Exposure of endothelial cells to estrogens increases NOS3 and COX1 expression and therefore raises the vasodilatory capacity. Studies looking at estrogen effects in an ovine model on NOS3 expression in high estrogen states such as the follicular phase of the menstrual cycle have clearly shown that estrogen promotes increased NOS3 expression, and this relates directly to increased NO output even without a change in $\mathrm{Ca}^{2+}$ bursting (Yi et al. 2005). However, in late pregnancy, much of the further increased NO production due to pregnancy adaptation occurs due to estrogenindependent changes in $\mathrm{Ca}^{2+}$ signaling. Estrogen may also promote vascular endothelial growth factor (VEGF) production by endothelial cells and so support vascular remodeling indirectly (Kazi \& Koos 2007).

Beyond ERA and ERB, others have sought to implicate the G-protein-coupled estrogen receptor, GPR30 in maternal regulation of blood flow, but species- and tissuespecific changes in GPR30 expression and action make for a controversial story. In the rat uterus, GPR30 has been implicated in estrogen-mediated reduction in vascular tone (Tropea et al. 2015), but some have suggested this may not be the case in humans (Corcoran et al. 2014). Others still have shown a role for GPR30 in regulation of vascular tone in human mammary arteries (Haas et al. 2009). It is critical that the switch from estrogens promoting angiogenesis to vasodilation occurs as gestation progresses because, as noted earlier, increases in uteroplacental blood flow become more reliant on vasodilation than angiogenesis. As estrogen levels rise dramatically through mid-gestation (O'Leary et al. 1991, Smith et al. 2009), it would be counterproductive for increased estrogen to drive angiogenesis as the fetus/ placenta drive vasodilation.

Progesterone Progesterone levels rise through pregnancy, elevating rapidly as the gestation nears term before crashing to allow parturition ( $\mathrm{O}^{\prime}$ Leary et al. 1991, Smith et al. 2009). Early in pregnancy, it is likely that progesterone plays a role in decidualization at the implantation site, as progesterone receptor is expressed in the endothelium of the decidua (Wang et al. 1992). Kristiansson and Wang (2001) correlated higher progesterone levels in early pregnancy with lower blood pressures later in pregnancy, though they were quick to point out the lack of causative evidence. Progesterone is also able to promote vasodilator production through the stimulation of NOS3 and thus NO production (Simoncini et al. 2007) as well as increased expression of activity of COX1, which regulates PGI2 production (Hermenegildo et al. 2005). This is not necessarily the case in all tissues, vascular beds, or models of pregnancy adaptation though. Others have shown rapid effects of progesterone on vascular tone through membrane-bound non-genomic progesterone receptors, which consist of rapid vasodilation responses (Thomas \& Pang 2013). In rats, progesterone blunted the pressor response to vasoconstrictors such as angiotensin II and norepinephrine (Nakamura et al. 1988, Novak \& Kaufman 1991). It is important to note that in the progesterone-dominated luteal phase in sheep, both NOS3 expression and $\mathrm{Ca}^{2+}$ responses are at a minimum in uterine artery endothelium itself (Yi et al. 2005),

Published by Bioscientifica Ltd. 
suggesting that elevated progesterone alone may not be a strong driver of vascular adaptation to pregnancy.

Androgens The role of androgens in pregnancy adaptation is poorly understood. It is possible that androgens play no discernible role in healthy vascular adaptation to pregnancy. There are, however, a handful of papers that point to androgens as a negative regulator of blood flow in PE pregnancies, which will be addressed in a later section.

\section{Cyclic nucleotides}

Both NO and PGI2 have been shown clearly to induce the production and secretion of both cGMP and cAMP in VSM (reviewed in Pelligrino \& Wang 1998). Cyclic nucleotides (cAMP and cGMP) are most well known as inhibitors of vascular tone in the VSM, but they can also play an important role in promoting the adaptation of endothelium. Part of sustaining uterine blood flow through sustained vasodilation requires the upregulation of functional CX43 in the plasma membrane. Cyclic nucleotides are also known to drive CX43 expression inside the cell as well as connexisome movement and placement into functional gap junction plaques in the plasma membrane (Paulson et al. 2000). The observations by Magness and coworkers that CX43 expression is increased in the uterine vascular endothelium along with NOS3 in late gestation (Morschauser et al. 2014) combined with our own observation of increased $\mathrm{Ca}^{2+}$ bursting in the same UA Endo preparations (Yi et al. 2010) suggest healthy vascular function may become self-reinforcing through cyclic nucleotide feed forward loop that will further amplify and sustain vasodilator production. This is particularly true in the uterine circulation where both NOS3 and CX43 expression is also elevated in the uterine artery closest to the site of placentation (Morschauser et al. 2014), but cyclic nucleotides spilling from the uterus may also explain pregnancy adaptive effects in the systemic circulation where substantial increases in cyclic nucleotides are still detectable (Shaul et al. 1992) and increased and more sustained $\mathrm{Ca}^{2+}$ signaling is also observed in maternal (Mahdy et al. 1998) and even fetal venous endothelium (Steinert et al. 2002).

\section{Hormones of inflammation}

Increasingly, and certainly in the last twenty years, normal pregnancy is acknowledged to be a mild inflammatory state (Conrad \& Benyo 1997, Tosun et al. 2010).
Immune cells and their byproducts are known to interact with invading trophoblasts and endothelial cells, and in most instances, this is a positive effect. In early pregnancy, immune cells play an important role in the implantation and establishment of the placenta. The decidua is known to contain a large number of immune cells, including helper T cells, natural killer cells, dendritic cells and macrophages (Ashkar et al. 2000, Hanna et al. 2006, Shimada et al. 2006, Plaks et al. 2008). These cells are known to produce many growth factors and cytokines including placental growth factor (PLGF), VEGF, tumor necrosis factor (TNF)A, interleukin (IL)1B, IL6, IL8, all of which may be important for establishing placentation and the neovascularization which accompanies it (Yang et al. 2003, Abrahams et al. 2004, Dekel et al. 2010). Additionally, these immune cell-derived growth factors and cytokines are important for vascular remodeling to provide adequate blood supply to the fetus, especially in response to hypoxic oxygen gradients (Page 2002, Kharfi et al. 2003). VEGF in particular is very well understood as a driver of angiogenesis and endothelial cell proliferation, which are central to vascular remodeling in pregnancy. VEGF is also known as a somewhat weak agonist for vasodilator production (through its ability to weakly mobilize $\mathrm{Ca}^{2+}$ ), and this may be beneficial for late-pregnancy support of uterine blood flow. Later in pregnancy, the role of inflammatory hormones is less well defined, though circulating concentrations change throughout gestation (Gillespie et al. 2016). Of note, abnormally high levels may even be detrimental.

\section{Preeclampsia}

Preeclampsia is a disease of human pregnancy typically characterized by hypertension and proteinuria. This disease is characterized by an insufficient drop in uterine vascular resistance, primarily in late gestation. Most reports estimate the incidence of $\mathrm{PE}$ at $3-5 \%$ of pregnancies in the United States and up to $10 \%$ of pregnancies worldwide (Wallis et al. 2008). PE is associated with both maternal and fetal morbidity and mortality. Up to $15 \%$ of global maternal deaths can be attributed to PE. Maternal morbidities include renal failure, liver failure, stroke and cardiac arrest (Matter \& Sibai 2000). Fetal complications are mostly the result of intrauterine growth restriction, preterm birth and can be severe enough for stillbirth (Jabeen et al. 2011). Early stages of the disease involve improper remodeling of the spiral arteries at the implantation site. Although the etiology of PE is still

Published by Bioscientifica Ltd 
debated, many believe it is often the result of improper immune and hormonal responses, which progress over the period of gestation, such that there is incomplete remodeling of the entire uterine vasculature, as well as corresponding endothelial dysfunction. Endothelial dysfunction as indicated by a lack of enhanced vasodilation is detected early in pregnancy and later dysfunction can include a breakdown of the endothelial monolayer and loss of vascular integrity, which is commonly reported in the clinic as proteinuria.

\section{Diagnosis and symptoms}

Mild PE is defined as gestational blood pressure greater than 140/90 on two separate occasions at a minimum of $4 \mathrm{~h}$ apart after 20 -week gestation along with proteinuria ( $>1+$ protein on dipstick or $>300 \mathrm{mg}$ in $24 \mathrm{~h}$ or protein/ creatinine ratio $\geq 0.3$ ) or in the absence of proteinuria, thrombocytopenia, renal insufficiency, impaired liver function, pulmonary edema, or cerebral or visual problems. Severe PE includes even higher blood pressure $(160 / 110)$ as well as confounding factors such as edema and seizures (Sibai et al. 2003). Current treatment often consists of antihypertensives, bed rest and ultimately caesarian section preterm delivery. Existing treatments, however, are for the symptoms and not the cause of PE. Antihypertensives are aimed at relaxing the vascular smooth muscle and commonly include use of nifedipine, an L-channel blocker. (This is not a problem from an endothelial standpoint as most capacitative $\mathrm{Ca}^{2+}$ entry in endothelial cells is mediated through TRPC channels (Gifford et al. 2006)). Nonetheless, control of the condition is a challenge to clinicians, and the symptoms of PE typically remain until delivery of the placenta, so posing a continuing threat to mother and child.

\section{Outcomes and long-term problems}

Beyond the immediate threat, there are also potential negative outcomes, or increased risk at the least, associated with $\mathrm{PE}$, which may surface later in life for both the mother and fetus. There is an increased risk of hypertension (3-fold, Canti etal.2012, Drost etal.2012) and cardiovascular disease (2-fold, Ray et al. 2005) later in life, in women who were diagnosed with PE. Although it may be argued PE indicated a predisposition to hypertension in the mother, other studies have also pointed to increased risk of hypertension and cardiovascular disease in children from PE pregnancies, especially among those who were delivered preterm (Irgens et al. 2001, Lawlor et al. 2012). Barker theorized that limited organ development and/or abnormal programming of organs and tissues occurs in such fetus and newborn infants gestated in the environment of a diseased pregnancy. Based on epidemiological studies from around the globe comparing birth records with adult-onset disease, he suggested that the uterus prepares the child for the world into which they will be born, and so these children would be maladapted for the 'normal' conditions outside the womb and would therefore be prone to disorders such as hypertension and heart disease later in life (Barker 1990). This theory has come to be commonly known as the Barker hypothesis and is often cited as a critical reason why diseases affecting the gestational environment must continue to be investigated, even if modern obstetric practices can reduce immediate perinatal mortality.

\section{Endothelial dysfunction in preeclampsia}

One enduring aspect of PE that has been studied intensively for decades is endothelial dysfunction. Endothelial dysfunction contributes to all major symptoms of PE (hypertension, edema, proteinuria and improper platelet aggregation). The key physiologic functions of endothelial cells to control vascular function by sensing the blood composition as well as providing a physical barrier to the improper movement of water, ions, proteins and cells from the blood into the vessel wall are likely compromised in PE. In that case, angiogenesis and vasodilation in response to stimuli such as decreased oxygen tension and mechanical stress due to shear forces would no longer be sufficient. It appears that this is a failure of endothelium to show normal pregnancy adaptation, given that PE subjects fail to develop insensitivity to vasoconstrictors, and both enhanced $\left[\mathrm{Ca}^{2+}\right]_{i}$ signaling and enhanced vasodilator production are reduced or lacking. The lower levels of circulating cyclic nucleotides also suggest feed-forward enhancement of endothelial cell coupling and so $\mathrm{Ca}^{2+}$ bursting is lost, and certainly, endothelial cells of PE subjects do show reduced $\mathrm{Ca}^{2+}$ bursting in parallel with reduced NO production (Krupp et al. 2013). The resulting increased blood volume of pregnancy and insufficient drops in uterine and systemic vascular resistance contribute greatly to the hypertensive component of PE. Other vascular beds also see a lack of vasodilator production, but may be especially sensitive to other measures of endothelial dysfunction. In the kidney, for example, glomerular endothelial cells often 
lose their barrier function integrity (beyond that of their typical fenestrations) and become pathologically permissive to protein movement into the urine (Wang et al. 2015). In extreme cases of endothelial monolayer barrier breakdown, at the blood-brain barrier, improper movement of proteins and ions can promote seizures (Hammer \& Cipolla 2015). Though often not as severe, these same effects can manifest in other parts of the body and in the extremities can result in edema (Brown 1995). Often a secondary result of endothelial dysfunction in $\mathrm{PE}$ is hyper coagulation due to release of thrombotic factors from damaged endothelial cells and increased leukocyte traffic to the injured tissue. We will not focus on thrombosis in PE in this review and instead refer to recent reviews in the area (Jodkowska et al. 2015). Taken together, the indicators of endothelial dysfunction in PE often feed forward onto each other, exacerbating the condition.

\section{Vasodilators in preeclampsia}

The central role that vasodilators play in pregnancy adaptation makes them a likely suspect as a culprit in the endothelial pathologies of PE. In fact, all three of the major vasodilators outlined previously as necessary components of normal pregnancy adaptations have been shown to be abnormally regulated in PE. It is important to note that although most studies in PE have focused on their role in uteroplacental tissues, many of the same deficiencies in vasodilator production are seen throughout the body.

Numerous studies have implicated decreased NO production or bioavailability in relation to $\mathrm{PE}$ pregnancies. Although no clear trend in NOS3 expression levels are observed, endothelial cells collected from PE pregnancies or exposed to maternal serum from PE pregnancies produce less $\mathrm{NO}$ than their counterparts from normal pregnancies (Hayman et al. 2000, Krupp et al. 2013). One study showed that even when NOS3 expression is increased in endothelial cells exposed to PE serum, overall bioavailability of NO may still be decreased due to increased arginase expression and increased asymmetric dimethylarginine observed in early-onset PE (Goulopoulou \& Davidge 2015). Shear stress-induced NO-dependent vasorelaxation is also reduced in human myometrial arteries from PE patients (Kublickiene et al. 2000). Others have shown that agonist-stimulated NO production in reduced in PE-derived endothelial cells. Akar and coworkers (1994) showed that there is some increase in basal NO production in umbilical arteries from PE pregnancies, but a decrease in the greater agonist-stimulated NO production. They reported no change in the umbilical vein, although this contrasts with other reports in the umbilical vein that clearly show that decreased agonist-stimulated NO production in umbilical vein endothelial cells derived from $\mathrm{PE}$ pregnancies relates directly to deficiencies in $\mathrm{Ca}^{2+}$ signaling (Steinert et al. 2002, Krupp et al. 2013). Mahdy et al. (1998) showed similar results for $\mathrm{Ca}^{2+}$ in human hand vein endothelial cells, suggesting that impaired $\mathrm{Ca}^{2+}$ signaling (and NO production) is not constrained to the maternal uterine and umbilical vasculature alone, but indeed extends to the maternal systemic arterial and venous vasculature as well.

Another potent vasodilator, PGI2, has also been shown extensively to be reduced in PE pregnancies, and this apparently precedes the development of PE. PGI2 itself has a very short half-life, but plasma and urinary concentrations of PGI2 metabolites are decreased in PE pregnancies due to widespread reductions in PGI2 production in many vascular beds, such as uterine, subcutaneous, placental and umbilical (Downing et al. 1980, Remuzzi et al. 1980). There are two predominant causes for decreased PGI2 production. Firstly, prostacyclin synthase, like NOS3 is dependent on increased intracellular $\mathrm{Ca}^{2+}$, and as Steinert, Mahdy and Krupp had have shown, $\mathrm{Ca}^{2+}$ signaling is impaired in endothelial cells from PE pregnancies (Mahdy et al. 1998, Steinert et al. 2002, Krupp et al. 2013). Second, increased oxidative stress associated with PE also inhibits prostacyclin synthase, thus reducing PGI2 production (Lorentzen et al. 1991, Baker et al. 1996). Much has also been written about TXA2/PGI2 ratio, which has been shown to be increased in PE due to both an increase in TXA2 production as well as in PGI2 reduction. However, it appears that decreased PGI2 may be more important physiologically, as low-dose aspirin administration to fight increased TXA2 levels while sparing PGI2 yields disappointing results in clinical trials (Sibai et al. 1993, Mills et al. 1999).

Although the imprecisely defined nature of EDHF makes it difficult to clearly state its role in the vascular pathogenesis of $\mathrm{PE}$, those that have undertaken this task have generally found EDHF-mediated vasorelaxation to be reduced in vessels from PE pregnancies. Luksha and coworkers $(2008,2009)$ have looked extensively at small subcutaneous and myometrial arteries from women with PE. They showed that myometrial arteries but not subcutaneous arteries have a reduced EDHF component in PE when compared with normal pregnancy. However, in the study on subcutaneous arteries, PE women could be broken down in to

Published by Bioscientifica Ltd 
subgroups based on their relative contribution of EDHF to vasorelaxation. In subcutaneous arteries, those with small contributions from EDHF were highly dependent on myoendothelial gap junctions, whereas those more dependent on EDHF were more dependent on $\mathrm{H}_{2} \mathrm{O}_{2}$ and arachidonic acid metabolites. In the myometrial arteries, the myoendthelial gap junctions played a very large role, but $\mathrm{H}_{2} \mathrm{O}_{2}$ may compensate to some degree in PE pregnancies. Another study on myometrial arteries also noted that EDHF is an important component of pregnancy adaptation, but appears to be missing in PE (Kenny et al. 2002). Overall, the loss of EDHFmediated vasorelaxation in PE may be more profound in smaller vessels, where the relative contribution of NO and PGI2 is typically reduced in favor of EDHF in normal pregnancy. Nonetheless, the common theme of EDHF function depending on gap junction function and the loss of EDHF function in PE is consistent with the observations regarding PE-associated loss of $\mathrm{NO}$ and PGI2 vasodilators.

\section{Hormones of preeclampsia-related endothelial dysfunction}

Although it is clear the failure to achieve proper endothelial adaptation is associated with PE, the question is why? The root cause of PE-related endothelial dysfunction has long been elusive, though many theories have been postulated. At this time, research in this field may best be summarized as a case of 'which came first, the chicken or the egg?' Nonetheless, once insufficient blood flow to the uterus is established as the norm, secondary events can contribute to maintaining a lack of endothelial adaptation otherwise so critical for healthy pregnancy. It is those adverse events which we now focus upon.

\section{Sex steroids and PE}

The role of estrogens and progesterone, despite their importance in pregnancy adaptation to at least control vasodilatory capacity in the uterine vascular endothelium, is unclear. This is partly due to complications in measuring free vs conjugated estrogens. Limited studies have shown a decrease in conjugated estrone and estriol, but not estradiol in peripheral serum from PE women (Rosing \& Carlstrom 1984). Others have shown decreased estradiol in urine, but serum levels of estrogens were unclear (reviewed in Rosing \& Carlstrom 1984).
Troisi and coworkers $(2003 a, b)$ investigated both maternal and cord blood serum from normal and PE pregnancies and showed no change in estrone, estradiol or estriol levels. The literature in progesterone levels in PE is also sparse. Rosing and Carlstrom (1984) found no change in unconjugated progesterone in PE pregnancies when compared with normal pregnancies.

There appears to be a more convincing case that androgens may play a role in the vascular pathology of PE. Androgens have been implicated in the promotion of hypertension, possibly through sensitization to pressors as well as decreased PGI2 production (Acromite et al. 1999), so it is therefore unsurprising that there may be a link between androgens and PE. Both androstenedione and testosterone in the unconjugated form were shown to be elevated in PE vs normal pregnancy (Troisi et al. 2003b), but were unchanged in cord blood serum. Others have also shown increased androgens in PE (Acromite et al. 1999, Salamalekis et al. 2006, Sharifzadeh et al. 2012) and has been linked to the dysregulation of p450 aromatase (Steier et al. 2002, Sathishkumar et al. 2012). Nonetheless, it is not clear how much this is a cause of PE and how much a consequence.

\section{Cyclic nucleotides}

Circulating levels of cyclic nucleotides are also a matter of conflicting results between multiple studies. Most studies looked at levels in maternal plasma and some have found increased cGMP (Schneider et al. 1996, Sandrim et al. 2011), whereas others see no significant change from normal pregnancy levels in PE pregnancy (Schiessl et al. 2006, Dusse et al. 2013). One study saw decreased cAMP levels in maternal plasma in PE pregnancies (Yamamoto et al. 2010). The relative lack of information on cyclic nucleotides in PE makes it difficult to draw any firm conclusions on what role they may or may not play in the vascular pathogenesis of PE. However, measurement of cyclic nucleotides suffers from differences in methods of detection, which is not such an issue in normal pregnancy adaptation where very large changes in circulating cyclic nucleotides are observed. One final point to note about the role of cyclic nucleotides in PE is that because they feed forward into CX43 function and $\mathrm{Ca}^{2+}$ signaling in normal pregnancy long term, the effect of any small loss in circulating levels may have a profound impact on endothelial cell function as that feed-forward support to adaptation is lost. (c) 2017 Society for Endocrinology Printed in Great Britain 


\section{Hormones of inflammation or hormones of wounding}

Preeclampsia has been described by some as an exaggerated state of inflammation (Mihu et al. 2015) and others have made the case that the endocrine profile of PE is similar to that of a non-healing wound (Bird et al. 2013). In this section, we will briefly review hormones of inflammation/wounding, which have been described as altered in PE compared with normal pregnancy and may have causative adverse effects on endothelial cell function. Other factors such as soluble endoglin (sEng), transforming growth factor (TGF)B and endothelin (ET)1 have been associated with $\mathrm{PE}$, and we refer to other recent reviews for more information on them (Liu et al. 2012, Saleh et al. 2016). We focus our attention instead on those factors, which are known to signal through common pathways or interact with the factors discussed through crosstalk or stimulation of secretion of discussed factors.

VEGF/PLGF/SFLT1 The role of VEGF family peptides and receptors in PE has been a controversial matter for some time and remains so today. Inconsistencies in gathering, measuring, and reporting circulating levels of VEGF have contributed greatly to the debate about just how much VEGF is present in normal and PE pregnancies and how much is freely available to bind the plasma membrane VEGF receptors of the endothelial cells. Many early studies measured total VEGF levels, but the discovery that circulating levels of the VEGFR1 splice variant, SFLT1, are increased in PE (Maynard et al. 2003) make interpretation of these early studies difficult because SFLT1 binds VEGF and renders it unable to bind to endothelial surface-bound VEGFR1 and VEGFR2. Even in those studies that measure total VEGF, there still remains no clear consensus as to whether circulating levels of total VEGF increase, decrease or remain unchanged in PE. Some variation in the use of ELISA assays, sandwich assays or more recent multiplex assays has not helped the situation. In those studies that looked specifically at free VEGF levels, maternal plasma and serum levels are often decreased in PE pregnancies (Maynard et al. 2003), which is thought to be due to increased SFLT1 levels. However, even these studies often fail to take into account the complexity of VEGF splice variants (e.g. VEGFA, the predominant human VEGF coding gene, is often used interchangeably with its 165 amino acid variant $\mathrm{VEGF}_{165}$, but other variants with biological activity such as $\mathrm{VEGF}_{189}$ and $\mathrm{VEGF}_{121}$ are also present in substantial levels). One isoform that seems to be gaining more widespread acceptance at least as a predictive marker in PE is circulating PLGF (which preferentially binds VEGFR1). In PE, PLGF levels are decreased, whether free or SFLT1 bound (Levine et al. 2004, Robinson et al. 2006) Certainly, recent prospective trials suggest the SFLT:PLGF ratio may have particular value as a predictive marker (Zeisler et al. 2016), whereas another study suggests a single marker (PLGF, SFLT or endoglin) may be effective (Duckworth et al. 2016). Others have reported that the predictive value even at 20-34 weeks was limited (Andersen et al. 2016). The discovery of $\mathrm{VEGF}_{165} \mathrm{~b}$ has further confused the picture regarding $V_{E G F}{ }_{165}$ because $\mathrm{VEGF}_{165}$ b has clearly been incorrectly assigned as $\mathrm{VEGF}_{165}$ in prior studies, and yet, $\mathrm{VEGF}_{165} \mathrm{~b}$ has different and even opposite effects on endothelial cell function (Bates 2011). Local concentrations of VEGF in PE can also vary in tissues beyond the placenta. For example, although histologic examination of PE placenta itself may show larger amounts of SFLT1 and reduced PLGF and VEGF (Yong et al. 2015), decidua and decidual immune cells, and perhaps even decidual endothelial cells show higher levels of VEGF release (Sharma et al. 2016). So one limitation in dissecting this problem is that studies need to look beyond the placenta and circulation alone and look further at the uterine environment also.

There is still genomic and transcriptomic evidence for altered placental and decidual VEGF expression (Soleymanlou et al. 2005, Yong et al. 2015, Sharma et al. 2016), and this alone makes a case to further study abnormal VEGF biosynthesis and action in the development of PE. Beyond the disagreements in the literature surrounding real circulating levels of VEGF in PE, there are also seemingly contradictory results regarding the functional consequences of exogenously altered VEGF levels on endothelial regulation of vascular tone. On the one hand, treatment of myometrial resistance arteries with VEGF mimicked the decrease in endotheliumdependent vasorelaxation typically observed with treatment with serum from PE pregnancies (Brockelsby et al. 1999, Hayman et al. 2000). On the other hand, rat studies have also shown that manipulation of VEGF and PLGF cause vasorelaxation, which can be antagonized by SFLT1 administration (Maynard et al. 2003). Although it may appear that these studies are contradictory, we would offer that they may not be. Rather it may be that optimal VEGF signaling is critical to healthy endothelial function and any deviance from that, whether it be increased VEGF or decreased free VEGF, it may cause changes in endothelial function, which are similar to those observed in PE pregnancies. Both additional clinical studies and additional exogenous manipulation of VEGF

Published by Bioscientifica Ltd 
and associated molecules will be necessary to unravel this problem in a meaningful way.

TNFA Elevated circulating levels of TNFA are also thought to have a direct effect on endothelial cell function by increasing vascular leakiness and reducing cell responsiveness to vasodilators. Two recent meta-analyses have assessed the levels of TNFA in maternal circulation (plasma and serum) in PE and normal pregnancies (Xie et al. 2011, Lau et al. 2013). Both studies confirmed that TNFA is upregulated in PE in the 3rd trimester. In addition, according to the meta-analyses, studies on circulating TNFA in early and mid-pregnancy (1st and 2nd trimesters) show mixed results, with some claiming elevated TNFA at this early point, whereas others show no difference; however, these studies are limited by small amounts of data compared with late pregnancy studies. A few studies that looked at mild vs severe PE saw no difference between the two groups in TNFA levels. However, one nonparametric study did show a significantly higher level of TNFA in the severe preeclamptic group (Lau et al. 2013). Others who looked at both maternal and umbilical serum also observed increased TNFA concentrations in PE when compared with normal pregnancy for both blood sample types (Tosun et al. 2010). It should be noted that, although TNFA can directly cause endothelial dysfunction, it is also known to promote the release of other factors known to have effects on endothelial function, such as PDGF, ET1 and IL6 (Conrad \& Benyo 1997).

Interleukins Numerous interleukins have been associated with PE. Those which have been most well studied are IL6, IL8 and IL10, although a few studies link other interleukins (i.e. IL1A and IL1B) with PE. Elevated maternal levels of both IL6 and IL8 have been extensively linked with PE. In two meta-analyses, IL6 was shown to be significantly elevated in the maternal circulation in PE compared with normal pregnancy (Xie et al. 2011, Lau et al. 2013). Tosun and coworkers (Tosun et al. 2010) also confirmed elevated levels of IL6 in maternal and umbilical serum. Although no meta-analysis was readily available for circulating levels of IL8 in PE, numerous studies are in agreement that IL8 is elevated in maternal blood from PE pregnancies compared with normal pregnancy (Redman \& Sargent 2003, Jonsson et al. 2006, Sharma et al. 2007, Tosun et al. 2010, Pinheiro et al. 2015). Additionally, some studies have implicated IL8 in recruitment and activation of immune cells such as neutrophils and T-lymphocytes (Mukaida et al. 1998, Sharma et al. 2007). A meta-analysis by Lau and coworkers (Lau et al. 2013) reported conflicting IL10 levels across the literature, with some reporting elevated IL10 levels in PE vs normal pregnancy and others showing decreased levels. On balance, they concluded that slightly more studies favored increased IL10 levels in PE. Another meta-analysis by Xie and coworkers (Xie et al. 2011) indicated that there was a significant trend in the literature toward elevated IL10 levels in maternal blood from PE pregnancies when compared with normal pregnancies.

INFG In a meta-analysis of 16 studies looking at maternal plasma and serum in normal and PE pregnancies by Yang and coworkers (Yang et al. 2014), there was a significant trend in the literature for increased interferon (INF)G levels in PE pregnancies. In 5 independent studies, however, there was no difference observed. Possible explanations for the heterogeneity of INFG data sets could be differences in patient population or differences in sample collection and/or handling.

\section{Effects of hormones of PE on the endothelium}

The hormones outlined previously, which are altered in PE compared with normal pregnancy with proper vascular adaptation to pregnancy can and do have consequences when it comes to endothelial cell function. The exact mechanism by which these hormones affect the maternal vascular endothelium are still being elucidated, but there is a growing body of evidence that aberrant growth factor and cytokine signaling in particular can bring about endothelial dysfunction in vivo and in vitro, which could contribute to two key symptoms of PE: hypertension and vascular leakiness. In an acute sense, improper growth factor and cytokine signaling can inhibit $\mathrm{Ca}^{2+}$ signaling events that are critical for vasodilator production through closure of existing gap junctions (Bird et al. 2013). Longterm stimulation of the same signaling pathways can then have more sustained and profound effects on endothelial monolayer integrity, and some studies suggest that this may be especially true in sensitive vascular beds such as the renal glomerulus (Turner et al. 2015, Xu et al. 2015). The proposed mechanisms for these effects are outlined in the following sections and are depicted in Fig. 1.

\section{Potential acute effects of hormones of PE on the endothelium}

Momentary changes in vessel diameter are critical to allow for rapid changes in blood flow. If a vessel loses the ability

Published by Bioscientifica Ltd. 


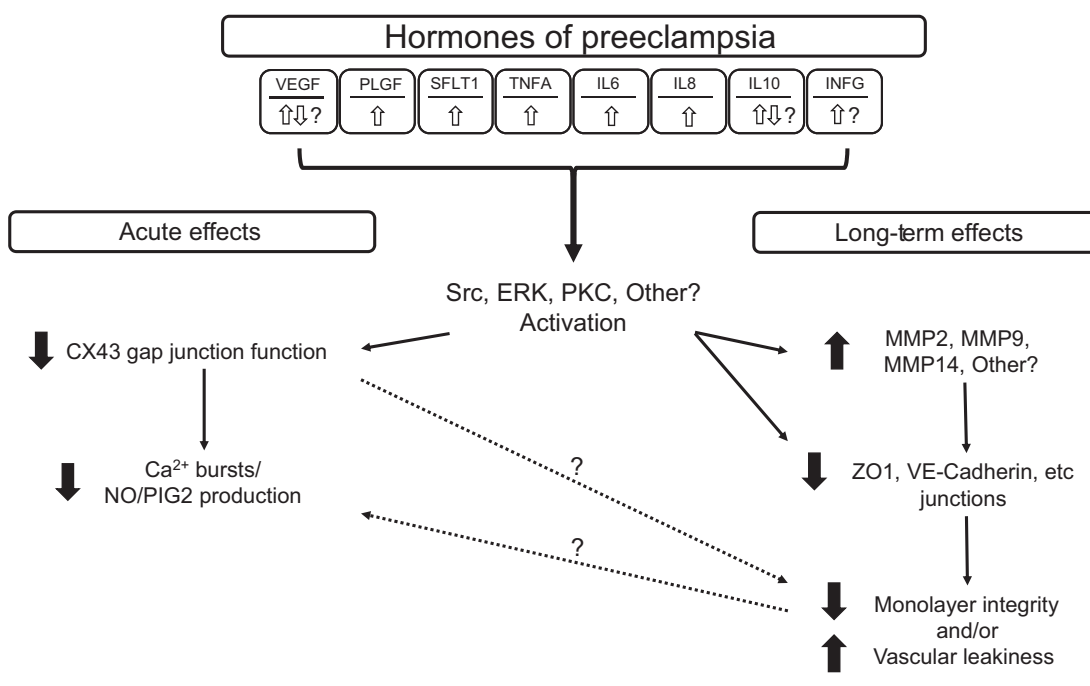

\section{Figure 1}

Proposed mechanism of endothelial dysfunction in preeclampsia. A diverse array of inflammatory hormones are altered in the circulation of late-term PE pregnancies compared with normal pregnancies. Together, these result in activation of kinase signaling pathways such as Src, ERK, PKC and possibly others. Activation of these pathways results in both acute and long-term changes at the level of the plasma membrane. Acutely, closure of CX43 alone results in immediate endothelial dysfunction by reducing the capacity of endothelial cells to coordinate $\mathrm{Ca}^{2+}$ responses needed to stimulate production of vasodilators (NO, PGI2). Longer term, further damage to cell junctional proteins such as ZO1 and VECadherin (by altered turnover or degradation by MMPs) causes a reduction in cell endothelial monolayer integrity and even vessel leakage (edema). to rapidly dilate when needed, hypertension may occur. A hallmark of PE is the inability of the vascular endothelium to produce the necessary vasodilators when called upon and in PE, gap junction-dependent $\mathrm{Ca}^{2+}$ signaling events may be insufficient for the production of the necessary amounts of vasodilators. Growing evidence now supports this theory. Studies on maternal hand vein endothelial cells and fetal umbilical vein endothelium from normal and PE pregnancies show a reduced capacity to sustain elevated $\left[\mathrm{Ca}^{2+}\right]_{\mathrm{i}}$ and produce NO (Mahdy et al. 1998, Steinert et al. 2002, Krupp et al. 2013). As PGI2 and some components of EDHF are $\mathrm{Ca}^{2+}$ sensitive, there is a strong likelihood this phenomenon extends to vasodilators more universally. The correlation between PE and reduced $\mathrm{Ca}^{2+}$ and vasodilator production is likely due to a link between $\mathrm{Ca}^{2+}$ signaling, gap junction communication and changes in the hormonal milieu during PE. As sustained endothelial $\mathrm{Ca}^{2+}$ signaling is dependent on CX43 gap junction function, CX43 emerged as a likely target for aberrant cell signaling events downstream of membrane-bound growth factor and cytokine receptors. Many groups (Warn-Cramer et al. 1996, Lampe \& Lau 2000, Suarez \& Ballmer-Hofer 2001, Solan \& Lampe 2005) have extensively shown that at least some of the growth factors and cytokines detailed previously have the ability to phosphorylate CX43 at residues on the C-terminus that render the protein less functional. Bird and coworkers have reviewed the link between hormones of PE and CX43 inhibition in detail (Bird et al. 2013). Common signaling 'culprits' that phosphorylate these inhibitory residues are Src, ERK and PKC (Bird et al. 2013). This has been corroborated in the ovine uterine artery endothelial cell model, where administration of VEGF leads to both phosphorylation of CX43 and reduced sustained phase
$\mathrm{Ca}^{2+}$ signaling (Boeldt et al. 2015). Inhibitors of Src and ERK signaling reversed the phosphorylation of CX43 at their respective target residues and also rescued $\mathrm{Ca}^{2+}$ signaling to levels equivalent to control (Boeldt et al. 2015). More detailed studies on other hormones (growth factors and cytokines) associated with of PE are warranted, to assess the universality of these initial observations, and whether they are indeed occurring in PE.

\section{Potential long-term effects of hormones of PE on the endothelium}

Over time, sustained exposure of the endothelium to high levels of growth factors and cytokines can also result in breakdown of endothelial monolayer integrity itself by degrading and/or removing cell junctional proteins. It is perhaps no coincidence because monolayer breakdown of endothelial cells can often be initiated through the same ERK and Src signaling pathways that act acutely on CX43 (reviewed in Bird et al. 2013). Such monolayer breakdown could explain other common symptoms of PE including proteinuria, edema, and in extreme cases, seizures due to blood-brain barrier breakdown. Cell-cell junctional proteins such as VE-cadherin and zonula occludens (ZO)1, which are commonly associated with plasma membrane CX43 function, are commonly targeted by excessive growth factors and cytokines for internalization and possible breakdown. This is coupled with a net reduction in peptide trafficking and membrane placement as cyclic nucleotides decline would result in an inability of neighboring cells to remain anchored to each other. Without a strongly tethered junctional complex, cells begin to retract. Although retraction is critical to initiate angiogenesis and wound healing in a non-pregnancy

Published by Bioscientifica Ltd 
setting, in late pregnancy when the uterine vasculature in particular has switched from being angiogenic to vasodilatory function, this response can only contribute to endothelial dysfunction and lead to vascular leakiness. Glomerular endothelial cells and podocytes may be to be especially sensitive to these signals, potentially explaining the high incidence of proteinuria in PE (Turner et al. 2015, Xu et al. 2015).

Matrix metalloproteinases (MMP) are one class of enzymes involved in the cleaving of cell-cell junctional proteins, which are linked with PE. As with many factors linked with PE, timing and location of MMP expression are incredibly important. One case in point is MMP14 (MT-MMP1), which can activate MMP2. Early in pregnancy MMP14 is critical for trophoblast invasion (Onogi et al. 2011). In pregnancies which are destined to become PE, MMP14 expression is decreased. However, in pregnancies already diagnosed with PE (by definition mid to late pregnancy), MMP14 has been observed to be increased (Kaitu'u-Lino et al. 2012). Others have implicated both MMP2 and MMP9 as critical for trophoblast invasion. Trophoblasts initially secrete large amounts of MMP2 and then relatively less MMP2 and more MMP9 through early pregnancy with normal gestation (Xu et al. 2000), but secrete less MMP2 and less MMP9 with PE pregnancy associated with growth restriction (Zhu et al. 2014). Of interest, studies in the reduced uterine perfusion pressure (RUPP) model of PE suggest that decreases in MMP2 and MMP9 may be seen in the systemic vasculature (aorta) as well as in the uterus and placenta and can be modulated by VEGF and SFLT1 (Li et al. 2014). At the level of endothelial cells themselves, MMP2, MMP9 and MMP14 all play a role in normal angiogenesis, and a part of that process can include the release of local surface bound growth factors (including VEGF) and TNFA (Pepper 2001). Abnormally elevated TNFA in turn can stimulate damage to cell monolayer integrity of blood-brain barrier endothelial cells through $\mathrm{ZO} 1$ breakdown, and this effect is apparently mediated by MMP9 (Wiggins-Dohlvik et al. 2014).

\section{Other areas for future study}

One remaining yet little explored consideration in discussing growth factors and cytokines linked with PE is that they often regulate the expression and secretion of each other. When this is coupled with immune cell migration to areas of inflammation or endothelial distress, which in turn secrete additional cytokines, the inflammatory condition at least locally, can become all the more severe. The study of such interacting cell types is limited in studies of pregnancy, but one example, which illustrates this concept is the crosstalk between INFG and IL6 through signal transducer and activator of transcription (STAT) signaling in atherosclerosis. In this condition, T cell secretion of INFG changes IL6 from an anti-inflammatory signal to a pro-inflammatory signal by shifting IL6 from a STAT3-mediated response to a STAT1 pathway (Sikorski et al. 2011). IL6 operating through STAT1 promotes immune cell adhesion to the endothelium, which could then have profound effects on local concentration of immune cell-secreted factors and inflammatory signal amplification. Clearly, this is an area for further study and further review.

\section{Integrated discussion}

Our ability to understand and treat PE depends heavily on our understanding of vascular adaptations in healthy pregnancies. Our understanding of the physiology of pregnancy adaptation quite often depends on the use of animal models, which may or may not fully represent the human condition. Furthermore, our understanding of cellular and molecular regulation of pregnancy adaptation is in its infancy. However, a common theme in both maternal vascular adaptation to pregnancy and the development and diagnosis of PE is the role of the vascular endothelium. It is apparent that many hormones related to pregnancy adaptation have profound effects on the endothelium, so perhaps it is no surprise that these very same hormones are often dysregulated in PE. The more our attention is drawn to the hormones of pregnancy adaptation and those altered in PE, the more we appreciate the complex environment they exist within. There is a tendency in clinical medicine to seek out the simple blood test but to date the use of such an approach has failed to be of diagnostic value. It is becoming increasingly clear the reason lies in the fact that adaptation to pregnancy and disorders of $\mathrm{PE}$ are not just confined to the placenta itself. Different tissues and vascular beds may experience altered local and circulating hormones in unique ways based upon local environment (hypoxia, cell state and status of invading immune cells). Multiple tissues and cell types such as trophoblasts, the decidua, the placenta, immune components and the endothelium itself all interact with each other, sometimes cross-talking through known signaling pathways like Src or as yet unexplored pathways 
such as STAT are amplifying local signals to respond disproportionately to circulating levels of hormone. This coupled with redundant cell signaling among growth factors and cytokines linked with PE, means that looking for a single hormone cause or biomarker for PE may be futile. Indeed, there are many ways each of the hormones outlined in this review could all contribute to the same clinical phenotype. Although individual hormones could vary between human subjects, outcomes could be similar. However, working backward from the symptoms of PE has also led us to these very convergence points on which endothelial cell function depends. Vasodilator production depends on $\mathrm{Ca}^{2+}$ signaling and endothelial cell barrier function depends largely on monolayer integrity. These two endothelial functions are also linked, as $\mathrm{Ca}^{2+}$ signaling depends on cell-cell junctional proteins such as CX43 gap junctions. Thus, if the complex and indeed variable cocktail of hormones, which are dysregulated in PE could be pharmacologically targeted not at the level of hormone production, but at a convergence point of hormone signaling, heterogeneity in patient endocrine profiles may become less of an issue. Studies to better understand the functional consequences of complex hormone environments are warranted to test the efficacy of this approach.

\section{Declaration of interest}

The authors declare that there is no conflict of interest that could be perceived as prejudicing the impartiality of this review.

\section{Funding}

This work was made possible with funding from NIH grants (R03HD079856 and P01HD38843) as well as NIHT32HD041921 for predoctoral training for D S B. Additional training support for D S B was from University of Wisconsin SMPH Herman I Shapiro Distinguished Graduate Fellowship.

\section{References}

Abrahams VM, Kim YM, Straszewski SL, Romero R \& Mor G 2004 Macrophages and apoptotic cell clearance during pregnancy. American Journal of Reproductive Immunology 51 275-282. (doi:10.1111/j.16000897.2004.00156.x)

Acromite MT, Mantzoros CS, Leach RE, Hurwitz J \& Dorey LG 1999 Androgens in preeclampsia. American Journal of Obstetrics and Gynecology 180 60-63. (doi:10.1016/S0002-9378(99)70150-X)

Akar F, Ark M, Uydes BS, Soysal ME, Saracoglu F, Abacioglu N, Van de Voorde J \& Kanzik I 1994 Nitric oxide production by human umbilical vessels in severe pre-eclampsia. Journal of Hypertension 12 1235-1241. (doi:10.1097/00004872-199411000-00005)

Andersen LB, Dechend R, Jorgensen JS, Luef BM, Nielsen J, Barington T \& Christesen HT 2016 Prediction of preeclampsia with angiogenic biomarkers. Results from the prospective Odense Child Cohort. Hypertension in Pregnancy 35 405-419. (doi:10.3109/10641955.2016. 1167219).

Ashkar AA, Di Santo JP \& Croy BA 2000 Interferon gamma contributes to initiation of uterine vascular modification, decidual integrity, and uterine natural killer cell maturation during normal murine pregnancy. Journal of Experimental Medicine 192 259-270. (doi:10.1084/jem.192.2.259)

Baker PN, Davidge ST, Barankiewicz J \& Roberts JM 1996 Plasma of preeclamptic women stimulates and then inhibits endothelial prostacyclin. Hypertension 27 56-61. (doi:10.1161/01.HYP.27.1.56)

Barker DJ 1990 The fetal and infant origins of adult disease. BMJ 301 1111. (doi:10.1136/bmj.301.6761.1111)

Bates DO 2011 An unexpected tail of VEGF and PIGF in pre-eclampsia. Biochemical Society Transactions 39 1576-1582. (doi:10.1042/ BST20110671)

Bird IM, Boeldt DS, Krupp J, Grummer MA, Yi FX \& Magness RR 2013 Pregnancy, programming and preeclampsia: gap junctions at the nexus of pregnancy-induced adaptation of endothelial function and endothelial adaptive failure in PE. Current Vascular Pharmacology 11 712-729. (doi:10.2174/1570161111311050009)

Bird IM, Sullivan JA, Di T, Cale JM, Zhang L, Zheng J \& Magness RR 2000 Pregnancy-dependent changes in cell signaling underlie changes in differential control of vasodilator production in uterine artery endothelial cells. Endocrinology 141 1107. (doi:10.1210/ en.141.3.1107)

Bird IM, Zhang L \& Magness RR 2003 Possible mechanisms underlying pregnancy-induced changes in uterine artery endothelial function. American Journal of Physiology: Regulatory, Integrative and Comparative Physiology 284 R245. (doi:10.1152/ajpregu.00108.2002)

Boeldt DS, Grummer MA, Yi F, Magness RR \& Bird IM 2015 Phosphorylation of Ser-279/282 and Tyr-265 positions on Cx43 as possible mediators of VEGF-165 inhibition of pregnancy-adapted $\mathrm{Ca} 2+$ burst function in ovine uterine artery endothelial cells. Molecular and Cellular Endocrinology 412 73-84. (doi:10.1016/j. mce.2015.05.030)

Boeldt DS, Yi FX \& Bird IM 2011 eNOS activation and NO function: pregnancy adaptive programming of capacitative entry responses alters nitric oxide (NO) output in vascular endothelium - new insights into eNOS regulation through adaptive cell signaling. Journal of Endocrinology 210 243. (doi:10.1530/JOE-11-0053)

Brockelsby J, Hayman R, Ahmed A, Warren A, Johnson I \& Baker P 1999 VEGF via VEGF receptor-1 (Flt-1) mimics preeclamptic plasma in inhibiting uterine blood vessel relaxation in pregnancy: implications in the pathogenesis of preeclampsia. Laboratory Investigation 791101.

Brown MA 1995 The physiology of pre-eclampsia. Clinical and Experimental Pharmacology and Physiology 22781. (doi:10.1111/j.1440-1681.1995.tb01937.x)

Cale JM \& Bird IM 2006 Dissociation of endothelial nitric oxide synthase phosphorylation and activity in uterine artery endothelial cells. American Journal of Physiology: Heart and Circulatory Physiology 290 H1433. (doi:10.1152/ajpheart.00942.2005)

Canti V, Maggio L, Ramirez GA, Locatelli A, Cozzolino S, Ramoni V, Ruffatti A, Tonello M, Valsecchi L, Rosa S, et al. 2012 Hypertension negatively affects the pregnancy outcome in patients with antiphospholipid syndrome. Lupus 21810. (doi:10.1177/0961203312441269)

Chen DB, Bird IM, Zheng J \& Magness RR 2004 Membrane estrogen receptor-dependent extracellular signal-regulated kinase pathway mediates acute activation of endothelial nitric oxide synthase by estrogen in uterine artery endothelial cells. Endocrinology 145 113-125. (doi:10.1210/en.2003-0547)

Clark SL, Cotton DB, Lee W, Bishop C, Hill T, Southwick J, Pivarnik J, Spillman T, DeVore GR \& Phelan J 1989 Central hemodynamic assessment of normal term pregnancy. American Journal of Obstetrics and Gynecology 161 1439. (doi:10.1016/0002-9378(89)90900-9) http://joe.endocrinology-journals.org

DOI: $10.1530 / J O E-16-0340$ (c) 2017 Society for Endocrinology Printed in Great Britain 
Conrad KP \& Benyo DF 1997 Placental cytokines and the pathogenesis of preeclampsia. American Journal of Reproductive Immunology $\mathbf{3 7}$ 240-249. (doi:10.1111/j.1600-0897.1997.tb00222.x)

Corcoran JJ, Nicholson C, Sweeney M, Charnock JC, Robson SC, Westwood M \& Taggart MJ 2014 Human uterine and placental arteries exhibit tissue-specific acute responses to 17beta-estradiol and estrogen-receptor-specific agonists. Molecular Human Reproduction 20 433-441. (doi:10.1093/molehr/gat095)

Das A, Mantena SR, Kannan A, Evans DB, Bagchi MK \& Bagchi IC 2009 De novo synthesis of estrogen in pregnant uterus is critical for stromal decidualization and angiogenesis. PNAS 106 12542-12547. (doi:10.1073/pnas.0901647106)

Dekel N, Gnainsky Y, Granot I \& Mor G 2010 Inflammation and implantation. American Journal of Reproductive Immunology 63 17-21. (doi:10.1111/j.1600-0897.2009.00792.x)

Downing I, Shepherd GL \& Lewis PJ 1980 Reduced prostacyclin production in pre-eclampsia. Lancet 2 1374. (doi:10.1016/S01406736(80)92443-5)

Drost JT, Arpaci G, Ottervanger JP, de Boer MJ, van Eyck J, van der Schouw YT \& Maas AH 2012 Cardiovascular risk factors in women 10 years post early preeclampsia: the Preeclampsia Risk EValuation in FEMales study (PREVFEM). European Journal of Preventive Cardiology 19 1138. (doi:10.1177/1741826711421079)

Duckworth S, Griffin M, Seed PT, North R, Myers J, Mackillop L, Simpson N, Waugh J, Anumba D, Kenny LC, et al. 2016 Diagnostic biomarkers in women with suspected preeclampsia in a prospective multicenter study. Obstetrics and Gynecology 128 245-252. (doi:10.1097/AOG.0000000000001508)

Dusse LM, Alpoim PN, Lwaleed BA, de Sousa LP, Carvalho M \& Gomes KB 2013 Is there a link between endothelial dysfunction, coagulation activation and nitric oxide synthesis in preeclampsia? Clinica Chimica Acta 415 226-229. (doi:10.1016/j.cca.2012.10.006)

Fraser HM \& Lunn SF 2000 Angiogenesis and its control in the female reproductive system. British Medical Bulletin 56787. (doi:10.1258/0007142001903364)

Gifford SM, Yi FX \& Bird IM 2006 Pregnancy-enhanced store-operated $\mathrm{Ca} 2+$ channel function in uterine artery endothelial cells is associated with enhanced agonist-specific transient receptor potential channel 3-inositol 1,4,5-trisphosphate receptor 2 interaction. Journal of Endocrinology 190 385. (doi:10.1677/joe.1.06773)

Gillespie SL, Porter K \& Christian LM 2016 Adaptation of the inflammatory immune response across pregnancy and postpartum in Black and White women. Journal of Reproductive Immunology $\mathbf{1 1 4}$ 27-31. (doi:10.1016/j.jri.2016.02.001)

Goodman RP, Killam AP, Brash AR \& Branch RA 1982 Prostacyclin production during pregnancy: comparison of production during normal pregnancy and pregnancy complicated by hypertension. American Journal of Obstetrics and Gynecology 142 817-822.

Goulopoulou S \& Davidge ST 2015 Molecular mechanisms of maternal vascular dysfunction in preeclampsia. Trends in Molecular Medicine 21 88-97. (doi:10.1016/j.molmed.2014.11.009)

Griffith TM 2004 Endothelium-dependent smooth muscle hyperpolarization: do gap junctions provide a unifying hypothesis? British Journal of Pharmacology 141 881-903. (doi:10.1038/ sj.bjp.0705698)

Haas E, Bhattacharya I, Brailoiu E, Damjanovic M, Brailoiu GC, Gao X, Mueller-Guerre L, Marjon NA, Gut A, Minotti R, et al. 2009 Regulatory role of $\mathrm{G}$ protein-coupled estrogen receptor for vascular function and obesity. Circulation Research 104 288-291. (doi:10.1161/ CIRCRESAHA.108.190892)

Habermehl DA, Janowiak MA, Vagnoni KE, Bird IM \& Magness RR 2000 Endothelial vasodilator production by uterine and systemic arteries. IV. Cyclooxygenase isoform expression during the ovarian cycle and pregnancy in sheep. Biology of Reproduction 62 781. (doi:10.1095/ biolreprod62.3.781)
Hammer ES \& Cipolla MJ 2015 Cerebrovascular dysfunction in preeclamptic pregnancies. Current Hypertension Reports 1764. (doi:10.1007/s11906-015-0575-8)

Hanna J, Goldman-Wohl D, Hamani Y, Avraham I, Greenfield C, Natanson-Yaron S, Prus D, Cohen-Daniel L, Arnon TI, Manaster I, et al. 2006 Decidual NK cells regulate key developmental processes at the human fetal-maternal interface. Nature Medicine 12 1065-1074. (doi:10.1038/nm1452)

Hayman R, Warren A, Brockelsby J, Johnson I \& Baker P 2000 Plasma from women with pre-eclampsia induces an in vitro alteration in the endothelium-dependent behaviour of myometrial resistance arteries. BJOG 107 108. (doi:10.1111/j.1471-0528.2000.tb11586.x)

Hermenegildo C, Oviedo PJ, Garcia-Martinez MC, Garcia-Perez MA, Tarin JJ \& Cano A 2005 Progestogens stimulate prostacyclin production by human endothelial cells. Human Reproduction 20 1554-1561. (doi:10.1093/humrep/deh803)

Irgens HU, Reisaeter L, Irgens LM \& Lie RT 2001 Long term mortality of mothers and fathers after pre-eclampsia: population based cohort study. BMJ 323 1213. (doi:10.1136/bmj.323.7323.1213)

Jabeen M, Yakoob MY, Imdad A \& Bhutta ZA 2011 Impact of interventions to prevent and manage preeclampsia and eclampsia on stillbirths. BMC Public Health 11 (Supplement 3) S6. (doi:10.1186/1471-2458-11-S3-S6)

Janowiak MA, Magness RR, Habermehl DA \& Bird IM 1998 Pregnancy increases ovine uterine artery endothelial cyclooxygenase-1 expression. Endocrinology 139 765. (doi:10.1210/en.139.2.765)

Jodkowska A, Martynowicz H, Kaczmarek-Wdowiak B \& Mazur G 2015 Thrombocytopenia in pregnancy - pathogenesis and diagnostic approach. Postępy Higieny i Medycyny Doświadczalnej 69 1215-1221. (doi:10.5604/17322693.1179649)

Jonsson Y, Ruber M, Matthiesen L, Berg G, Nieminen K, Sharma S, Ernerudh J \& Ekerfelt C 2006 Cytokine mapping of sera from women with preeclampsia and normal pregnancies. Journal of Reproductive Immunology 70 83-91. (doi:10.1016/j.jri.2005.10.007)

Kaitu'u-Lino TJ, Palmer KR, Whitehead CL, Williams E, Lappas M \& Tong S 2012 MMP-14 is expressed in preeclamptic placentas and mediates release of soluble endoglin. American Journal of Pathology 180 888-894. (doi:10.1016/j.ajpath.2011.11.014)

Kazi AA \& Koos RD 2007 Estrogen-induced activation of hypoxiainducible factor-1alpha, vascular endothelial growth factor expression, and edema in the uterus are mediated by the phosphatidylinositol 3-kinase/Akt pathway. Endocrinology 148 2363-2374. (doi:10.1210/en.2006-1394)

Kenny LC, Baker PN, Kendall DA, Randall MD \& Dunn WR 2002 The role of gap junctions in mediating endothelium-dependent responses to bradykinin in myometrial small arteries isolated from pregnant women. British Journal of Pharmacology 136 1085-1088. (doi:10.1038/ sj.bjp.0704817)

Kharfi A, Giguère Y, Sapin V, Massé J, Dastugue B \& Forest JC 2003 Trophoblastic remodeling in normal and preeclamptic pregnancies: implication of cytokines. Clinical Biochemistry 36 323-331. (doi:10.1016/S0009-9120(03)00060-2)

Kristiansson P \& Wang JX 2001 Reproductive hormones and blood pressure during pregnancy. Human Reproduction 16 13-17. (doi:10.1093/humrep/16.1.13)

Krupp J, Boeldt DS, Yi FX, Grummer MA, Bankowski Anaya HA, Shah DM \& Bird IM 2013 The loss of sustained $\mathrm{Ca}(2+)$ signaling underlies suppressed endothelial nitric oxide production in preeclamptic pregnancies: implications for new therapy. American Journal of Physiology: Heart and Circulatory Physiology 305 H969-H979. (doi:10.1152/ajpheart.00250.2013)

Kublickiene KR, Lindblom B, Kruger K \& Nisell H 2000 Preeclampsia: evidence for impaired shear stress-mediated nitric oxide release in uterine circulation. American Journal of Obstetrics and Gynecology 183 160-166. (doi:10.1016/S0002-9378(00)41620-0) http://joe.endocrinology-journals.org

DOI: $10.1530 / \mathrm{JOE}-16-0340$
() 2017 Society for Endocrinology Printed in Great Britain 
Lampe PD \& Lau AF 2000 Regulation of gap junctions by phosphorylation of connexins. Archives of Biochemistry and Biophysics 384 205. (doi:10.1006/abbi.2000.2131)

Lau SY, Guild SJ, Barrett CJ, Chen Q, McCowan L, Jordan V \& Chamley LW 2013 Tumor necrosis factor-alpha, interleukin-6, and interleukin-10 levels are altered in preeclampsia: a systematic review and meta-analysis. American Journal of Reproductive Immunology $\mathbf{7 0}$ 412-427. (doi:10.1111/aji.12138)

Lawlor DA, Macdonald-Wallis C, Fraser A, Nelson SM, Hingorani A, Davey Smith G, Sattar N \& Deanfield J 2012 Cardiovascular biomarkers and vascular function during childhood in the offspring of mothers with hypertensive disorders of pregnancy: findings from the Avon Longitudinal Study of Parents and Children. European Heart Journal 33 335. (doi:10.1093/eurheartj/ehr300)

Levine RJ, Maynard SE, Qian C, Lim KH, England LJ, Yu KF, Schisterman EF, Thadhani R, Sachs BP, Epstein FH, et al. 2004 Circulating angiogenic factors and the risk of preeclampsia. New England Journal of Medicine 350 672. (doi:10.1056/NEJMoa031884)

Lewis PJ, Boylan P, Friedman LA, Hensby CN \& Downing I 1980 Prostacyclin in pregnancy. British Medical Journal 280 1581-1582. (doi:10.1136/bmj.280.6231.1581)

Li W, Mata KM, Mazzuca MQ \& Khalil RA 2014 Altered matrix metalloproteinase-2 and -9 expression/activity links placental ischemia and anti-angiogenic sFlt-1 to uteroplacental and vascular remodeling and collagen deposition in hypertensive pregnancy. Biochemical Pharmacology 89 370-385. (doi:10.1016/j. bcp.2014.03.017)

Liu Z, Afink GB \& Dijke PT 2012 Soluble fms-like tyrosine kinase 1 and soluble endoglin are elevated circulating anti-angiogenic factors in pre-eclampsia. Pregnancy Hypertension 2 358-367. (doi:10.1016/j. preghy.2012.06.003)

Lorentzen B, Endresen MJ, Hovig T, Haug E \& Henriksen T 1991 Sera from preeclamptic women increase the content of triglycerides and reduce the release of prostacyclin in cultured endothelial cells. Thrombosis Research 63 363-372. (doi:10.1016/00493848(91)90139-N)

Luksha L, Agewall S \& Kublickiene K 2009 Endothelium-derived hyperpolarizing factor in vascular physiology and cardiovascular disease. Atherosclerosis 202 330-344. (doi:10.1016/j. atherosclerosis.2008.06.008)

Luksha L, Nisell H, Luksha N, Kublickas M, Hultenby K \& Kublickiene K 2008 Endothelium-derived hyperpolarizing factor in preeclampsia: heterogeneous contribution, mechanisms, and morphological prerequisites. American Journal of Physiology: Regulatory, Integrative and Comparative Physiology 294 R510-R519. (doi:10.1152/ ajpregu.00458.2007)

Magness RR, Shaw CE, Phernetton TM, Zheng J \& Bird IM 1997 Endothelial vasodilator production by uterine and systemic arteries. II. Pregnancy effects on NO synthase expression. American Journal of Physiology 272 H1730.

Magness RR, Shideman CR, Habermehl DA, Sullivan JA \& Bird IM 2000 Endothelial vasodilator production by uterine and systemic arteries. V. Effects of ovariectomy, the ovarian cycle, and pregnancy on prostacyclin synthase expression. Prostaglandins and Other Lipid Mediators 60 103. (doi:10.1016/S0090-6980(99)00055-6)

Magness RR \& Zheng J 1996 Maternal cardiovascular alterations during pregnancy. In Pediatric and Perinatal Perspectives, p 762. Ed MA Heymann \& PD Gluckman. London, UK: Edward Arnold Publishers.

Mahdy Z, Otun HA, Dunlop W \& Gillespie JI 1998 The responsiveness of isolated human hand vein endothelial cells in normal pregnancy and in pre-eclampsia. Journal of Physiology $\mathbf{5 0 8} 609$. (doi:10.1111/j.14697793.1998.00609.x)

Matter F \& Sibai BM 2000 Eclampsia. VIII. Risk factors for maternal morbidity. American Journal of Obstetrics and Gynecology 182 307-312. (doi:10.1016/S0002-9378(00)70216-X)
Maynard SE, Min JY, Merchan J, Lim KH, Li J, Mondal S, Libermann TA, Morgan JP, Sellke FW, Stillman IE, et al. 2003 Excess placental soluble fms-like tyrosine kinase 1 (sFlt1) may contribute to endothelial dysfunction, hypertension, and proteinuria in preeclampsia. Journal of Clinical Investigation 111 649. (doi:10.1172/JCI17189)

Mehta PK \& Griendling KK 2007 Angiotensin II cell signaling: physiological and pathological effects in the cardiovascular system. American Journal of Physiology: Cell Physiology 292 C82. (doi:10.1152/ ajpcell.00287.2006)

Mihu D, Razvan C, Malutan A \& Mihaela C 2015 Evaluation of maternal systemic inflammatory response in preeclampsia. Taiwanese Journal of Obstetrics and Gynecology 54 160-166. (doi:10.1016/j. tjog.2014.03.006)

Mills JL, DerSimonian R, Raymond E, Morrow JD, Roberts LJ 2nd, Clemens JD, Hauth JC, Catalano P, Sibai B, Curet LB, et al. 1999 Prostacyclin and thromboxane changes predating clinical onset of preeclampsia: a multicenter prospective study. JAMA 282 356-362.

Morschauser TJ, Ramadoss J, Koch JM, Yi FX, Lopez GE, Bird IM \& Magness RR 2014 Local effects of pregnancy on connexin proteins that mediate Ca2+-associated uterine endothelial NO synthesis. Hypertension 63 589-594. (doi:10.1161/HYPERTENSIONAHA.113.01171)

Morton JS \& Davidge ST 2013 Arterial endothelium-derived hyperpolarization: potential role in pregnancy adaptations and complications. Journal of Cardiovascular Pharmacology 61 197-203. (doi:10.1097/FJC.0b013e31827b6367)

Mukaida N, Harada A \& Matsushima K 1998 Interleukin-8 (IL-8) and monocyte chemotactic and activating factor (MCAF/MCP-1), chemokines essentially involved in inflammatory and immune reactions. Cytokine and Growth Factor Reviews 9 9-23. (doi:10.1016/ S1359-6101(97)00022-1)

Nakamura T, Matsui K, Ito M, Yoshimura T, Kawasaki N, Fujisaki S \& Okamura H 1988 Effects of pregnancy and hormone treatments on pressor response to angiotensin II in conscious rats. American Journal of Obstetrics and Gynecology 159 989-995. (doi:10.1016/S00029378(88)80186-8)

Novak K \& Kaufman S 1991 Effects of pregnancy, estradiol, and progesterone on pressor responsiveness to angiotensin II. American Journal of Physiology 261 R1164-R1170.

O'Leary P, Boyne P, Flett P, Beilby J \& James I 1991 Longitudinal assessment of changes in reproductive hormones during normal pregnancy. Clinical Chemistry 37 667-672.

Onogi A, Naruse K, Sado T, Tsunemi T, Shigetomi H, Noguchi T, Yamada Y, Akasaki M, Oi H \& Kobayashi H 2011 Hypoxia inhibits invasion of extravillous trophoblast cells through reduction of matrix metalloproteinase (MMP)-2 activation in the early first trimester of human pregnancy. Placenta 32 665-670. (doi:10.1016/j. placenta.2011.06.023)

Osol G \& Mandala M 2009 Maternal uterine vascular remodeling during pregnancy. Physiology 24 58-71. (doi:10.1152/physiol.00033.2008)

Page EW, Vilee CA \& Vilee DB 1972 Physiological adjustments in pregnancy in human reproduction: the core content of obstetrics, gynecology, and perinatal medicine, p 253. Philadelphia, PA, USA: WB Saunders Company.

Page NM 2002 The endocrinology of pre-eclampsia. Clinical Endocrinology 57 413-423. (doi:10.1046/j.1365-2265.2002.01626.x)

Palmer SK, Zamudio S, Coffin C, Parker S, Stamm E \& Moore LG 1992 Quantitative estimation of human uterine artery blood flow and pelvic blood flow redistribution in pregnancy. Obstetrics and Gynecology 80 1000-1006.

Paulson AF, Lampe PD, Meyer RA, TenBroek E, Atkinson MM, Walseth TF \& Johnson RG 2000 Cyclic AMP and LDL trigger a rapid enhancement in gap junction assembly through a stimulation of connexin trafficking. Journal of Cell Science 1133037.

Pelligrino DA \& Wang Q 1998 Cyclic nucleotide crosstalk and the regulation of cerebral vasodilation. Progress in Neurobiology 56 1-18. (doi:10.1016/S0301-0082(98)00009-4) 
Pepper MS 1997 Manipulating angiogenesis. From basic science to the bedside. Arteriosclerosis, Thrombosis, and Vascular Biology 17605 (doi:10.1161/01.ATV.17.4.605)

Pepper MS 2001 Role of the matrix metalloproteinase and plasminogen activator-plasmin systems in angiogenesis. Arteriosclerosis, Thrombosis, and Vascular Biology 21 1104-1117. (doi:10.1161/ hq0701.093685)

Pinheiro MB, Gomes KB, Ronda CR, Guimaraes GG, Freitas LG, Teixeira-Carvalho A, Martins-Filho OA \& Dusse LM 2015 Severe preeclampsia: association of genes polymorphisms and maternal cytokines production in Brazilian population. Cytokine 71 232-237. (doi:10.1016/j.cyto.2014.10.021)

Plaks V, Birnberg T, Berkutzki T, Sela S, BenYashar A, Kalchenko V, Mor G, Keshet E, Dekel N, Neeman M, et al. 2008 Uterine DCs are crucial for decidua formation during embryo implantation in mice. Journal of Clinical Investigation 118 3954-3965. (doi:10.1172/JCI36682)

Poston L, McCarthy AL \& Ritter JM 1995 Control of vascular resistance in the maternal and feto-placental arterial beds. Pharmacology and Therapeutics 65 215-239. (doi:10.1016/0163-7258(94)00064-A)

Ray JG, Vermeulen MJ, Schull MJ \& Redelmeier DA 2005 Cardiovascular health after maternal placental syndromes (CHAMPS): populationbased retrospective cohort study. Lancet 366 1797. (doi:10.1016/ S0140-6736(05)67726-4)

Redman CW \& Sargent IL 2003 Pre-eclampsia, the placenta and the maternal systemic inflammatory response - a review. Placenta 24 S21. (doi:10.1053/plac.2002.0930)

Remuzzi G, Marchesi D, Zoja C, Muratore D, Mecca G, Misiani R, Rossi E, Barbato M, Capetta P, Donati MB, et al. 1980 Reduced umbilical and placental vascular prostacyclin in severe pre-eclampsia. Prostaglandins 20 105-110. (doi:10.1016/0090-6980(80)90010-6)

Robertson WB, Brosens I \& Dixon G 1975 Uteroplacental vascular pathology. European Journal of Obstetrics \& Gynecology and Reproductive Biology 5 47. (doi:10.1016/0028-2243(75)90130-6)

Robinson CJ, Johnson DD, Chang EY, Armstrong DM \& Wang W 2006 Evaluation of placenta growth factor and soluble Fms-like tyrosine kinase 1 receptor levels in mild and severe preeclampsia. American Journal of Obstetrics and Gynecology 195 255-259. (doi:10.1016/j. ajog.2005.12.049)

Rosing U \& Carlstrom K 1984 Serum levels of unconjugated and total oestrogens and dehydroepiandrosterone, progesterone and urinary oestriol excretion in pre-eclampsia. Gynecologic and Obstetric Investigation 18 199-205. (doi:10.1159/000299081)

Salamalekis E, Bakas P, Vitoratos N, Eleptheriadis M \& Creatsas G 2006 Androgen levels in the third trimester of pregnancy in patients with preeclampsia. European Journal of Obstetrics \& Gynecology and Reproductive Biology 126 16-19. (doi:10.1016/j.ejogrb.2005.07.007)

Saleh L, Verdonk K, Visser W, van den Meiracker AH \& Danser AH 2016 The emerging role of endothelin-1 in the pathogenesis of preeclampsia. Therapeutic Advances in Cardiovascular Disease 10 282-293. (doi:10.1177/1753944715624853)

Sandrim VC, Palei AC, Sertorio JT, Amaral LM, Cavalli RC \& TanusSantos JE 2011 Alterations in cyclic GMP levels in preeclampsia may reflect increased B-type natriuretic peptide levels and not impaired nitric oxide activity. Clinical Biochemistry 44 1012-1014. (doi:10.1016/j.clinbiochem.2011.05.026)

Sathishkumar K, Balakrishnan M, Chinnathambi V, Chauhan M, Hankins GD \& Yallampalli C 2012 Fetal sex-related dysregulation in testosterone production and their receptor expression in the human placenta with preeclampsia. Journal of Perinatology 32 328-335. (doi:10.1038/jp.2011.101)

Schiessl B, Strasburger C, Bidlingmaier M, Mylonas I, Jeschke U, Kainer F \& Friese K 2006 Plasma- and urine concentrations of nitrite/nitrate and cyclic Guanosinemonophosphate in intrauterine growth restricted and preeclamptic pregnancies. Archives of Gynecology and Obstetrics 274 150. (doi:10.1007/s00404-006-0149-8)
Schneider F, Lutun P, Baldauf JJ, Quirin L, Dreyfus M, Ritter J \& Tempe JD 1996 Plasma cyclic GMP concentrations and their relationship with changes of blood pressure levels in preeclampsia. Acta Obstetricia et Gynecologica Scandinavica 75 40-44. (doi:10.3109/00016349609033281)

Sharifzadeh F, Kashanian M \& Fatemi F 2012 A comparison of serum androgens in pre-eclamptic and normotensive pregnant women during the third trimester of pregnancy. Gynecological Endocrinology 28 834-836. (doi:10.3109/09513590.2012.683061)

Sharma A, Satyam A \& Sharma JB 2007 Leptin, IL-10 and inflammatory markers (TNF-alpha, IL-6 and IL-8) in pre-eclamptic, normotensive pregnant and healthy non-pregnant women. American Journal of Reproductive Immunology 58 21-30. (doi:10.1111/j.16000897.2007.00486.x)

Sharma S, Godbole G \& Modi D 2016 Decidual control of trophoblast invasion. American Journal of Reproductive Immunology 75 341-350. (doi:10.1111/aji.12466)

Shaul PW, Farrar MA \& Magness RR 1992 Prostacyclin synthesis and stimulation of cyclic AMP production in ovine fetal vasculature: heterogeneity in pulmonary and systemic arteries. Developmental Pharmacology and Therapeutics 18 89-99.

Shimada S, Nishida R, Takeda M, Iwabuchi K, Kishi R, Onoe K, Minakami H \& Yamada H 2006 Natural killer, natural killer $\mathrm{T}$, helper and cytotoxic $\mathrm{T}$ cells in the decidua from sporadic miscarriage. American Journal of Reproductive Immunology 56 193-200. (doi:10.1111/j.1600-0897.2006.00417.x)

Sibai BM, Caritis S, Hauth J \& National Institute of Child Health and Human Development Maternal-Fetal Medicine Units Network 2003 What we have learned about preeclampsia. Seminars in Perinatology $\mathbf{2 7}$ 239. (doi:10.1016/S0146-0005(03)00022-3)

Sibai BM, Caritis SN, Thom E, Klebanoff M, McNellis D, Rocco L, Paul RH, Romero R, Witter F, Rosen M, et al. 1993 Prevention of preeclampsia with low-dose aspirin in healthy, nulliparous pregnant women. The National Institute of Child Health and Human Development Network of Maternal-Fetal Medicine Units. New England Journal of Medicine 329 1213-1218. (doi:10.1056/NEJM199310213291701)

Sikorski K, Czerwoniec A, Bujnicki JM, Wesoly J \& Bluyssen HA 2011 STAT1 as a novel therapeutical target in pro-atherogenic signal integration of IFNgamma, TLR4 and IL-6 in vascular disease. Cytokine and Growth Factor Reviews 22 211-219. (doi:10.1016/j.cytogfr.2011.06.003)

Simoncini T, Fu XD, Caruso A, Garibaldi S, Baldacci C, Giretti MS, Mannella P, Flamini MI, Sanchez AM \& Genazzani AR 2007 Drospirenone increases endothelial nitric oxide synthesis via a combined action on progesterone and mineralocorticoid receptors. Human Reproduction 22 2325-2334. (doi:10.1093/humrep/dem109)

Sladek SM, Magness RR \& Conrad KP 1997 Nitric oxide and pregnancy. American Journal of Physiology 272 R441.

Smith R, Smith JI, Shen X, Engel PJ, Bowman ME, McGrath SA, Bisits AM, McElduff P, Giles WB \& Smith DW 2009 Patterns of plasma corticotropin-releasing hormone, progesterone, estradiol, and estriol change and the onset of human labor. Journal of Clinical Endocrinology and Metabolism 94 2066-2074. (doi:10.1210/jc.2008-2257)

Solan JL \& Lampe PD 2005 Connexin phosphorylation as a regulatory event linked to gap junction channel assembly. Biochimica et Biophysica Acta 1711 154. (doi:10.1016/j.bbamem.2004.09.013)

Soleymanlou N, Jurisica I, Nevo O, Ietta F, Zhang X, Zamudio S, Post M \& Caniggia I 2005 Molecular evidence of placental hypoxia in preeclampsia. Journal of Clinical Endocrinology and Metabolism 90 4299. (doi:10.1210/jc.2005-0078)

Steier JA, Ulstein M \& Myking OL 2002 Human chorionic gonadotropin and testosterone in normal and preeclamptic pregnancies in relation to fetal sex. Obstetrics and Gynecology 100 552-556. (doi:10.1097/00006250-200209000-00024)

Steinert JR, Wyatt AW, Poston L, Jacob R \& Mann GE 2002 Preeclampsia is associated with altered $\mathrm{Ca} 2+$ regulation and $\mathrm{NO}$ production http://joe.endocrinology-journals.org

DOI: $10.1530 / J O E-16-0340$
() 2017 Society for Endocrinology Printed in Great Britain 
in human fetal venous endothelial cells. FASEB Journal 16721. (doi:10.1096/fj.01-0916fje)

Suarez S \& Ballmer-Hofer K 2001 VEGF transiently disrupts gap junctional communication in endothelial cells. Journal of Cell Science 1141229.

Sullivan JA, Grummer MA, Yi FX \& Bird IM 2006 Pregnancy-enhanced endothelial nitric oxide synthase (eNOS) activation in uterine artery endothelial cells shows altered sensitivity to Ca2+, U0126, and wortmannin but not LY294002--evidence that pregnancy adaptation of eNOS activation occurs at multiple levels of cell signaling. Endocrinology 147 2442. (doi:10.1210/en.2005-0399)

Suzuki Y, Hattori T, Kajikuri J, Yamamoto T, Suzumori K \& Itoh T 2002 Reduced function of endothelial prostacyclin in human omental resistance arteries in pre-eclampsia. Journal of Physiology 545 269-277. (doi:10.1113/jphysiol.2002.022384)

Thomas P \& Pang Y 2013 Protective actions of progesterone in the cardiovascular system: potential role of membrane progesterone receptors (mPRs) in mediating rapid effects. Steroids $\mathbf{7 8} 583-588$. (doi:10.1016/j.steroids.2013.01.003)

Tosun M, Celik H, Avci B, Yavuz E, Alper T \& Malatyalioglu E 2010 Maternal and umbilical serum levels of interleukin-6, interleukin-8, and tumor necrosis factor-alpha in normal pregnancies and in pregnancies complicated by preeclampsia. Journal of Maternal-Fetal and Neonatal Medicine 23 880-886. (doi:10.3109/14767051003774942)

Tran QK, Leonard J, Black DJ, Nadeau OW, Boulatnikov IG \& Persechini A 2009 Effects of combined phosphorylation at Ser-617 and Ser-1179 in endothelial nitric-oxide synthase on EC50(Ca2+) values for calmodulin binding and enzyme activation. Journal of Biological Chemistry 284 11892. (doi:10.1074/jbc.M806205200)

Troisi R, Potischman N, Johnson CN, Roberts JM, Lykins D, Harger G, Markovic N, Siiteri P \& Hoover RN 2003a Estrogen and androgen concentrations are not lower in the umbilical cord serum of preeclamptic pregnancies. Cancer Epidemiology, Biomarkers and Prevention 12 1268-1270.

Troisi R, Potischman N, Roberts JM, Ness R, Crombleholme W, Lykins D, Siiteri P \& Hoover RN 2003b Maternal serum oestrogen and androgen concentrations in preeclamptic and uncomplicated pregnancies. International Journal of Epidemiology 32 455-460. (doi:10.1093/ije/ dyg094)

Tropea T, De Francesco EM, Rigiracciolo D, Maggiolini M, Wareing M, Osol G \& Mandala M 2015 Pregnancy augments G protein estrogen receptor (GPER) induced vasodilation in rat uterine arteries via the nitric oxide - cGMP signaling pathway. PLOS ONE 10 e0141997. (doi:10.1371/journal.pone.0141997)

Turner RJ, Bloemenkamp KW, Penning ME, Bruijn JA \& Baelde HJ 2015 From glomerular endothelium to podocyte pathobiology in preeclampsia: a paradigm shift. Current Hypertension Reports 1754. (doi:10.1007/s11906-015-0566-9)

Wallis AB, Saftlas AF, Hsia J \& Atrash HK 2008 Secular trends in the rates of preeclampsia, eclampsia, and gestational hypertension, United States, 1987-2004. American Journal of Hypertension 21 521-526. (doi:10.1038/ajh.2008.20)

Wang JD, Fu Y, Shi WL, Zhu PD, Cheng J, Qiao GM, Wang YQ \& Greene GL 1992 Immunohistochemical localization of progesterone receptor in human decidua of early pregnancy. Human Reproduction $\mathbf{7}$ 123-127.

Wang Y, Gu Y, Loyd S, Jia X \& Groome LJ 2015 Increased urinary levels of podocyte glycoproteins, matrix metallopeptidases, inflammatory cytokines, and kidney injury biomarkers in women with preeclampsia. American Journal of Physiology: Renal Physiology 309 F1009-F1017. (doi:10.1152/ajprenal.00257.2015)

Warn-Cramer BJ, Lampe PD, Kurata WE, Kanemitsu MY, Loo LW, Eckhart W \& Lau AF 1996 Characterization of the mitogenactivated protein kinase phosphorylation sites on the connexin-43 gap junction protein. Journal of Biological Chemistry 2713779. (doi:10.1074/jbc.271.7.3779)

Wiggins-Dohlvik K, Merriman M, Shaji CA, Alluri H, Grimsley M, Davis ML, Smith RW \& Tharakan B 2014 Tumor necrosis factor-alpha disruption of brain endothelial cell barrier is mediated through matrix metalloproteinase-9. American Journal of Surgery 208 954-960; discussion 960. (doi:10.1016/j.amjsurg.2014.08.014)

Xie C, Yao MZ, Liu JB \& Xiong LK 2011 A meta-analysis of tumor necrosis factor-alpha, interleukin-6, and interleukin-10 in preeclampsia. Cytokine 56 550-559. (doi:10.1016/j.cyto.2011.09.021)

Xu C, Wu X, Hack BK, Bao L \& Cunningham PN 2015 TNF causes changes in glomerular endothelial permeability and morphology through a Rho and myosin light chain kinase-dependent mechanism. Physiological Reports 3. (doi:10.14814/phy2.12636)

Xu P, Wang YL, Zhu SJ, Luo SY, Piao YS \& Zhuang LZ 2000 Expression of matrix metalloproteinase-2, -9 , and -14 , tissue inhibitors of metalloproteinase-1, and matrix proteins in human placenta during the first trimester. Biology of Reproduction 62 988-994. (doi:10.1095/ biolreprod62.4.988)

Yamamoto T, Suzuki Y, Kojima K, Suzumori N \& Suzuki T 2010 The biological investigation of prostacyclin in preeclamptic women seen reduced endothelial function. Hypertension in Pregnancy 29 484-491. (doi:10.3109/10641950903322873)

Yang W, Ahn H, Hinrichs M, Torry RJ \& Torry DS 2003 Evidence of a novel isoform of placenta growth factor (PlGF-4) expressed in human trophoblast and endothelial cells. Journal of Reproductive Immunology 60 53-60. (doi:10.1016/S0165-0378(03)00082-2)

Yang Y, Su X, Xu W \& Zhou R 2014 Interleukin-18 and interferon gamma levels in preeclampsia: a systematic review and meta-analysis. American Journal of Reproductive Immunology 72 504-514. (doi:10.1111/aji.12298)

Yi FX, Boeldt DS, Gifford SM, Sullivan JA, Grummer MA, Magness RR \& Bird IM 2010 Pregnancy enhances sustained Ca2+ bursts and endothelial nitric oxide synthase activation in ovine uterine artery endothelial cells through increased connexin 43 function. Biology of Reproduction 82 66. (doi:10.1095/biolreprod.109.078253)

Yi FX, Magness RR \& Bird IM 2005 Simultaneous imaging of Ca2+ i and intracellular NO production in freshly isolated uterine artery endothelial cells: effects of ovarian cycle and pregnancy. American Journal of Physiology: Regulatory, Integrative and Comparative Physiology 288 R140. (doi:10.1152/ajpregu.00302.2004)

Yong HE, Melton PE, Johnson MP, Freed KA, Kalionis B, Murthi P, Brennecke SP, Keogh RJ \& Moses EK 2015 Genome-wide transcriptome directed pathway analysis of maternal pre-eclampsia susceptibility genes. PLOS ONE 10 e0128230. (doi:10.1371/journal. pone.0128230)

Zeisler H, Llurba E, Chantraine F, Vatish M, Staff AC, Sennstrom M, Olovsson M, Brennecke SP, Stepan H, Allegranza D, et al. 2016 Predictive value of the sFlt-1:PlGF ratio in women with suspected preeclampsia. New England Journal of Medicine 374 13-22. (doi:10.1056/NEJMoa1414838)

Zhu J, Zhong M, Pang Z \& Yu Y 2014 Dysregulated expression of matrix metalloproteinases and their inhibitors may participate in the pathogenesis of pre-eclampsia and fetal growth restriction. Early Human Development 90 657-664. (doi:10.1016/j. earlhumdev.2014.08.007)

Received in final form 3 October 2016

Accepted 11 October 2016

Accepted Preprint published online 11 October 2016 http://joe.endocrinology-journals.org

DOI: 10.1530/JOE-16-0340
๑ 2017 Society for Endocrinology Printed in Great Britain 